\title{
Synoptic evolution of composite wet spells over northern Tanzania
}

\author{
T. A. Kabanda*, Mark R. Jury** \\ Geography Dept, Univ Zululand, KwaDlangezwa 3886, South Africa
}

\begin{abstract}
The synoptic-scale structure and evolution of wet spells over northern Tanzania are described. Pentad (5 d) ECMWF data for major convective events during November in the period 1986 to 1992 were averaged to form a sequential composite, and a seasonal reference mean is subtracted to produce anomalies. The composite results show that a NW-SE line of convergent moisture shifts southward from the NW Indian Ocean 2 pentads before the wet spell, while uplift occurs over the highlands to the north. A high-pressure cell intensifies in the SW Indian Ocean 1 pentad before the wet spell. During this time a low-level vorticity dipole is maintained in the west Indian Ocean, either side of the equator. The main flux of moisture is from the southern Indian Ocean. A southern subtropical, upper westerly trough amplifies during the onset phase. The results offer statistical guidance in medium-range weather forecasts that may assist agricultural management. Dynamical insights are also gained to improve knowledge of climate-weather teleconnections and tropicalsubtropical interactions.
\end{abstract}

KEY WORDS: Intra-seasonal oscillations $\cdot$ Rainfall $\cdot$ Tanzania

Resale or republication not permitted without written consent of the publisher

\section{INTRODUCTION AND BACKGROUND}

Rainy spells over tropical east Africa are associated with the inter-tropical convergence zone (ITCZ) and embedded clusters of deep cumulus convection. The ITCZ advances across Tanzania $\left(2-11^{\circ} \mathrm{S}, 30-38^{\circ} \mathrm{E}\right.$, Fig. 1) during November, resides south of the country in the austral summer, and retreats during April. The structure and intensity of ITCZ convection and its supporting circulation determine Tanzania's hydroelectric potential and agricultural output, which constitutes over $50 \%$ of gross domestic product.

Cumulative rainfall exceeds $1000 \mathrm{~mm}$ annually throughout much of Tanzania. The distribution of seasonal rainfall is bimodal and is made up of isolated extreme events and quasi-periodic widespread wet spells, the latter more conducive to higher crop yields. Occasionally the rains fail, often in association with cooling of sea-surface temperatures in the equatorial western Indian Ocean and reduced monsoon moisture

\footnotetext{
*Permanent affiliation: Tanzanian Directorate of Meteorology, Dar es Salaam, Tanzania

**Corresponding author. E-mail: mjury@pan.uzulu.ac.za
}

flux convergence (Cadet 1985, Hastenrath et al. 1993, Kabanda \& Jury 1999). Smoothed daily rainfall time series, averaged over groups of adjacent stations, give evidence for intra-seasonal cyclicity, whereby multiday periods of convective activity alternate with quiescent dry phases. This is particularly so in northern Tanzania during the October to December 'short' rainy season (Kabanda 1995).

Intra-seasonal oscillations in the atmosphere are generally defined as convective fluctuations with frequencies shorter than the seasonal cycle, of the order of 10 to $60 \mathrm{~d}$. Little work has been done with respect to the Tanzanian intra-seasonal climate, and this study fills a gap in the understanding. Efforts to understand the nearmonthly oscillation of summer weather over southern Africa were made by Levey (1993) and Makarau (1994). The rainy season there is typically comprised of 5 wet spells of 1 to 2 pentads duration, contributing $100 \mathrm{~mm}$ each. Circulation and thermodynamic mechanisms driving wet spells over southern Africa were inferred from composite pentad European Centre for Medium Range Weather Forecasts (ECMWF) anomalies.

Intra-seasonal oscillation studies which relate to tropical Africa and its adjacent oceans include that of Zhu 


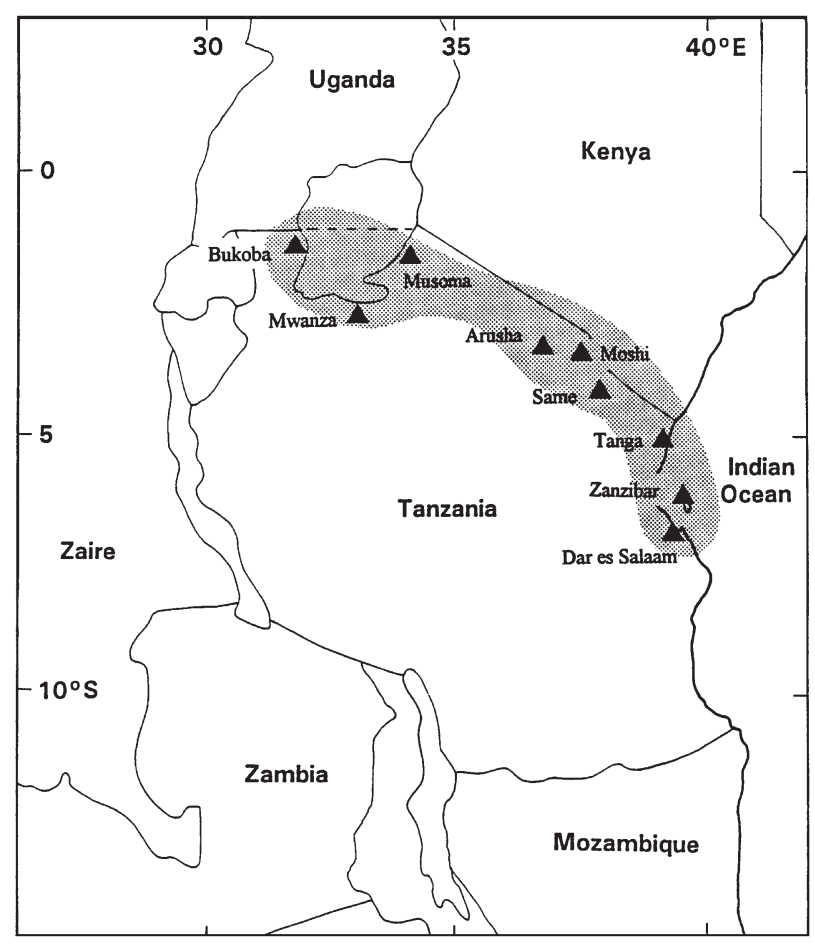

Fig. 1. Map of east Africa showing the 9 rainfall stations $(\mathbf{\Lambda})$ in northern Tanzania used for composite selection

\& Wang (1993), who found a prominent centre of action in the central Indian Ocean for 30 to $60 \mathrm{~d}$ convective variability. Rui \& Wang (1990) documented the development and dynamic structure of tropical intraseasonal convection anomalies using pentad outgoing longwave radiation (OLR) and ECMWF-derived 200 and $850 \mathrm{hPa}$ wind divergence. Murakami (1988), Anyamba (1992) and Matarira \& Jury (1992) have discussed intra-seasonal variability in the African sector; however, the evolution of synoptic-scale forcing and its relationship to local convection have not been described.

External precursors and regional controls of wet spells over tropical east Africa are documented here for the November onset event. Rainfall during this period contributes up to $40 \%$ of the annual total in northern Tanzania (Nyenzi 1988). Using principal component analysis, Ogallo (1989) found that the first principal component explained $70 \%$ of the total rainfall variance over tropical east Africa, with a bimodal distribution and widespread spatial loading. The short rains are associated with a shift of the ITCZ to south of the equator over the western Indian Ocean following dissipation over India (Asnani 1993). During the 'ITCZ onset event', which usually occurs in November, convection is concentrated over the plateau of northern Tanzania, and water resources, depleted during the preceding dry winter season, are replenished.
Tanzanian wet spells are hypothesised to be related to moisture advection from the western Indian Ocean, enhanced upper westerly shear and in situ convection due to local instability and heating. To diagnose the mechanisms underlying intra-seasonal variability, ECMWF gridded meteorological field data for the period 1986 to 1992 were used to provide insight into the synoptic-scale processes responsible for the formation, development and maturity of sustained and intense wet spells.

\section{DATA AND METHODS}

The rainfall data used in this study consist of daily totals for the 9 stations in northern Tanzania $\left(2-6^{\circ} \mathrm{S}\right.$, $32-40^{\circ} \mathrm{E}$ ) identified in Fig. 1. The station rainfall data are representative of a varied geography (i.e. coast, highlands and lake basin); however, smoothed time series from different stations are significantly crosscorrelated $(\mathrm{r} \approx 0.70, \mathrm{n}=18)$. Daily rainfall for the 9 stations, in the period of overlapping the ECMWF data, were averaged into pentads ( $5 \mathrm{~d}$ ) (see Fig. 2 for selection of cases).

ECMWF gridded information used in this study was taken from the uninitialised, $2.5^{\circ}$ resolution, standardlevel data for $12 Z$ time $(15: 00 \mathrm{~h}$ local) and includes the following parameters: geopotential height, zonal and meridional wind components, vertical motion, relative humidity, and temperature. Derived variables include wind divergence and vorticity, precipitable water, water vapour flux and the velocity potential. The levels 850,500 and $200 \mathrm{hPa}$ are used for the presentation of meteorological fields. Derived parameters are based on vertical integrals (to $500 \mathrm{hPa}$ ) or horizontal differentials. ECMWF fields were averaged into calendar pentads for analysis. Data were extracted for the October to December season over a domain extending from $20^{\circ} \mathrm{N}$ to $40^{\circ} \mathrm{S}$ and $30^{\circ} \mathrm{W}$ to $100^{\circ} \mathrm{E}$, including much of the South Atlantic Ocean, Africa and the Indian Ocean.

The ECMWF analysis system has been revised to improve operational forecasts. Changes made prior to 1989 have been discussed by Bengtsson \& Shukla (1988), Hoskins et al. (1989) and Klinker (1991). The revisions include improved humidity analysis via satellite precipitable water estimates; the introduction of improved spatial resolution and vertical model levels and refined structure functions; and the improved analysis of divergent wind. In the time since 1989 the convective scheme and surface fluxes have been refined.

The analysis of intra-seasonal oscillations is based on a pentad time frame, which highlights the gradual evolution of weather systems. Rainfall and ECMWF data 
Table 1. Cases selected to form pentad composites for analysis of the wet spell sequence in northern Tanzania. Values are numbers of pentads and years

\begin{tabular}{|ccc|}
\hline Dry phase (P2) & Onset phase (P1) & Wet phase (P0) \\
\hline $9-1986$ & $10-1986$ & $11-1986$ \\
$6-1988$ & $7-1988$ & $8-1988$ \\
$9-1989$ & $10-1989$ & $11-1989$ \\
$7-1990$ & $8,9-1990$ & $10-1990$ \\
$10-1991$ & & $11-1991$ \\
\hline
\end{tabular}

for the short rain season comprise 18 pentads, where the first pentad is 3 to 7 October and the last is 27 to 31 December. For case selection, pentad area-averaged rainfall had to exceed $25 \mathrm{~mm}$ during mid-season (e.g. November).

Following identification of the wet spell (defined as $\mathrm{P0)}$, the preceding pentads establish the precursor patterns in terms of onset (P1) and dry phases (P2). The composites are based on 5 major wet spells from all years except 1987, which was relatively dry. Seasonal means were determined by averaging all ECMWF data in the October to December period, comprising 552 days of input data. This reference mean was subtracted from the composite fields, constructed from 25 days, to produce anomalies. It is believed that a sequential analysis of anomaly maps consisting of 25 days' input data is sufficient to explore the evolution of wet spells. Table 1 illustrates the cases selected to form pentad composites for analysis. Although rainfall data were considered for 8 consecutive years, wet spells met the criteria in only 5 .

Composite meteorological patterns are expected to offer little guidance in medium-term weather forecasts as a result of the background circulation overwhelming the synoptic-scale signals. Skill would improve using statistical guidance from evolving anomaly patterns, hence our focus here.

\section{RESULTS}

Composite wet spell evolution is described in Section 3.2. We commence with an analysis of the intra-seasonal rainfall distribution during the case study period.

\subsection{Rainfall}

Fig. 2 shows the pentad area-averaged rainfall over the study period. The 1986 short rainy season was wet throughout, in contrast to 1987. Wet spells in 1988 peaked later in the season, whilst 1989 to 1992 had cyclic and intense wet spells with dry conditions early on. 1993 was another relatively dry season. October is generally dry and wet spells are irregular and of low intensity. The ITCZ is first noticeable usually in November, and rainfall rises to a peak then. A second wet spell occurs in December and often follows a rhythm and intensity established by the earlier wet spell. The wet spells appear modulated, in part, by eastwardmoving convective troughs which penetrate the equatorial band from the southern subtropics, as determined by the Hovmoller plots of various ECMWF meteorological anomalies analysed by Levey (1993).

The seasonal mean, which is used to establish anomaly patterns, is characterised by southern subtropical highs and a ridge over the Arabian Sea in the low levels. Westward water vapour fluxes from the equatorial Indian Ocean converge onto the ITCZ over the region where uplift is vigourous. Upper westerly shear is imposed by long-wave troughs extending from the southern subtropics from Madagascar to Tanzania. Further discussion of the seasonal climatology is not included for brevity.

\subsection{Evolution of wet spells}

The evolution of wet spells is described using composite sequences, where P2 refers to the pentad $10 \mathrm{~d}$ before the wet spell, P1 is $5 \mathrm{~d}$ before and P0 is the period of most active convection. The $850 \mathrm{hPa}$ geopotential height anomalies in Fig. 3a illustrate weak positive values in both hemispheres at P2. Negative anomalies (-25 gpm) lie along $40^{\circ} \mathrm{S}$ in a wavy pattern. At the upper level (200 hPa, Fig. 3b), a large negative anomaly is located southeast of Africa in the subtropics and extends northwards along the coast of east Africa. At the onset stage (P1) a positive anomaly (+25 gpm) grows at the $850 \mathrm{hPa}$ level to the southeast of Madagascar. The geopotential increase is also reflected in the northern hemisphere at similar longitudes -40 to $90^{\circ} \mathrm{E}$ - over the Indian Ocean. The $200 \mathrm{hPa}$ patterns show strong positive anomalies in the southern subtropics, with a peak of $+70 \mathrm{gpm}$ at $40^{\circ} \mathrm{S}, 60^{\circ} \mathrm{E}$ and in the South Atlantic Ocean. Negative anomalies occur over the southwest Indian Ocean and northeast Africa.

During the maturity stage (P0), a ridge extends zonally over and southeast of southern Africa at lower levels. Also apparent is a positive anomaly over the Arabian Sea and India. The tropical region displays weak negative geopotential anomalies, whilst upper levels show generally positive anomalies. An upper ridge is noted southwest of Africa. The areas south of Madagascar and in the northern subtropics along $15^{\circ} \mathrm{N}$ are occupied by negative anomalies at $200 \mathrm{hPa}$. A significant feature of the low-level geopotential sequence is the building of a high-pressure cell over the southwest 

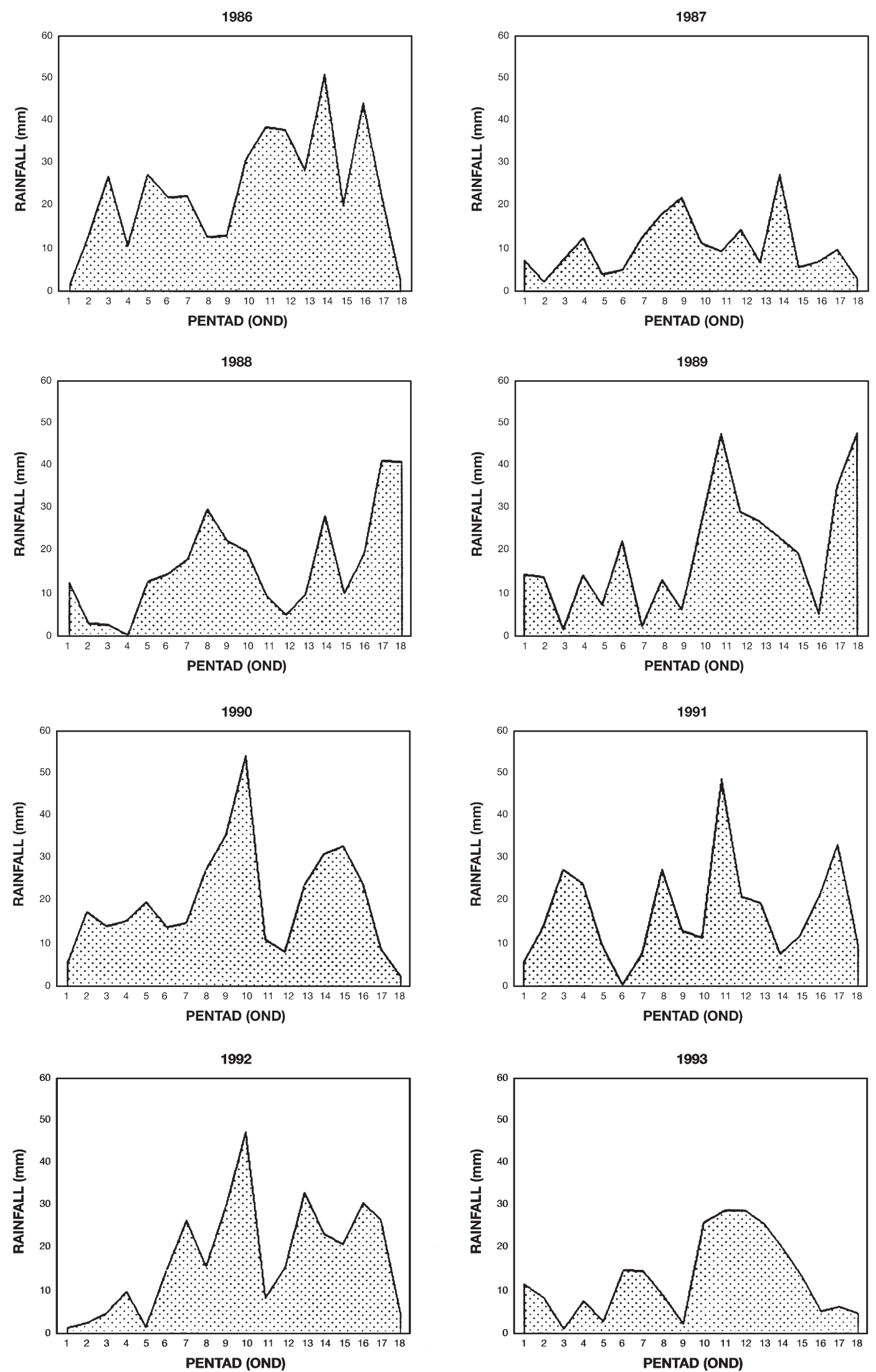

Fig. 2. Pentad area-averaged $\left(2-6^{\circ} \mathrm{S}, 32-40^{\circ} \mathrm{E}\right)$ time series for the short rain season (October to December) for each year between 1986 and 1993 

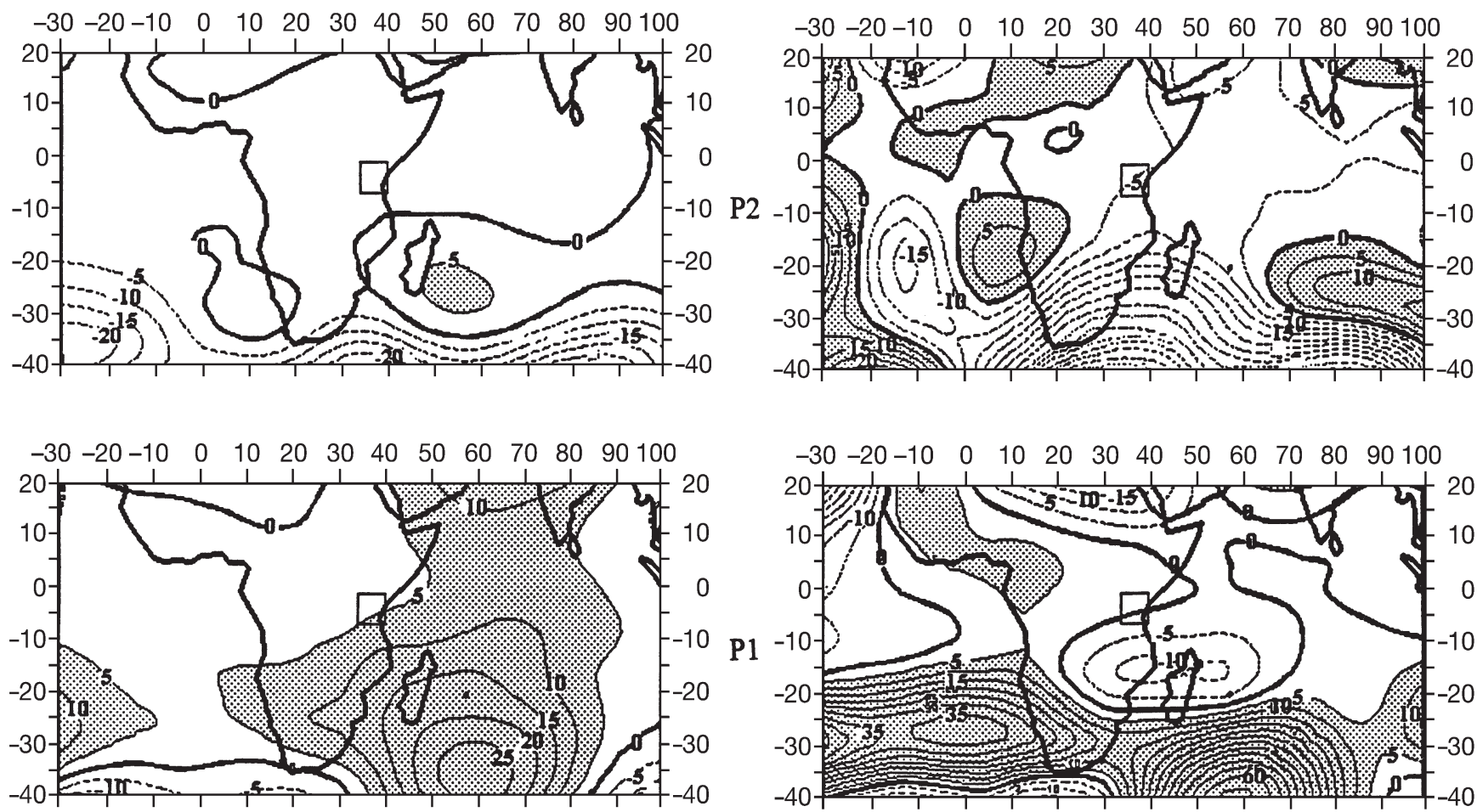

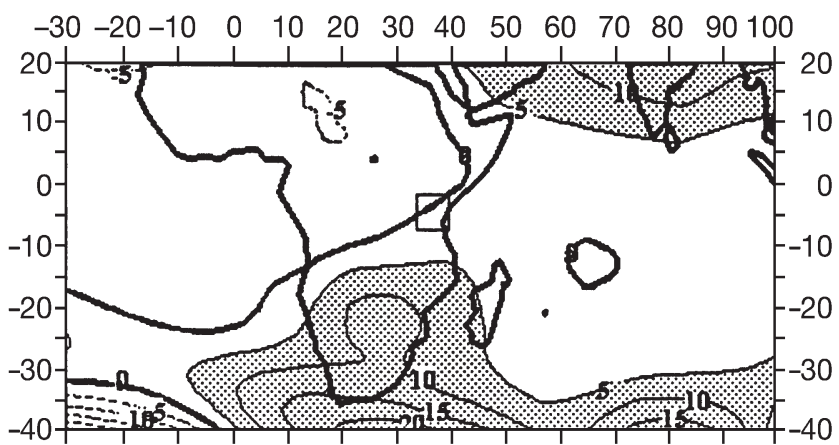

$\mathbf{a}$

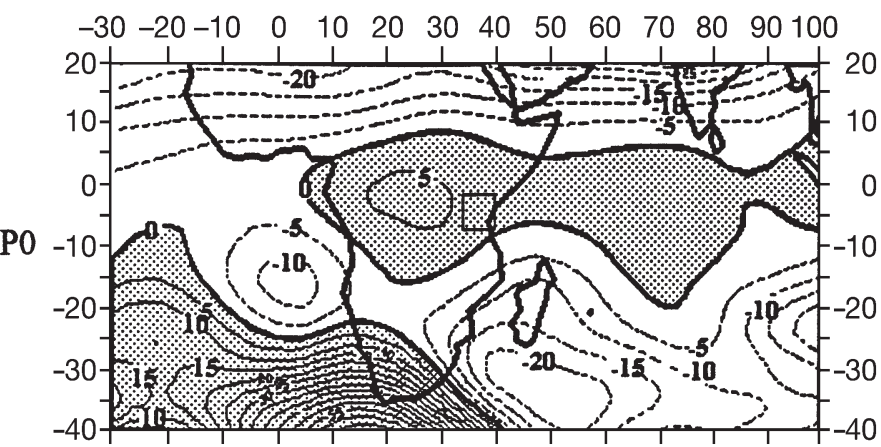

b

Fig. 3. Pentad anomalies for the composite wet spell sequence P2 (top), P1 (middle) and P0 (bottom) for geopotential height at (a) $850 \mathrm{hPa}$ and (b) $200 \mathrm{hPa}$. Contour interval is $5 \mathrm{gpm}$

Indian Ocean and to lesser extent over the Arabian Sea.

Fig. 4a illustrates the water vapour flux (WVF) anomalies integrated from the surface to $500 \mathrm{hPa}$, and Fig. 4b the $200 \mathrm{hPa}$ wind anomalies. Together these allow inferences to be drawn about the synoptic circulation anomalies surrounding the wet spell. It is evident that northeasterly and southeasterly fluxes converge onto the east African coast near the equator at the formation stage (P2). The WVF anomalies are weak owing to the disorganised structure of the subtropical anticyclones at that stage. Upper wind anomalies
$(200 \mathrm{hPa})$ at the formation stage (Fig. 4b) reveal a strong anticyclonic circulation over Angola and a cyclonic gyre over the Arabian Peninsula. Weak westerly anomalies prevail along the equator of east Africa. WVF anomalies of $100 \mathrm{~g} \mathrm{~kg}^{-1} \mathrm{~m} \mathrm{~s}^{-1}$ prevail over Tanzania during the onset stage (P1) as the Mascarene anticyclone strengthens over the southwest Indian Ocean. Confluent moist flow shifts to east Africa during this phase. During the maturity stage (P0), northeasterly anomalies from the Arabian Sea dominate as southeasterlies weaken. Anomalous westerward fluxes from each hemisphere maintain confluence along $5^{\circ} \mathrm{S}$. 

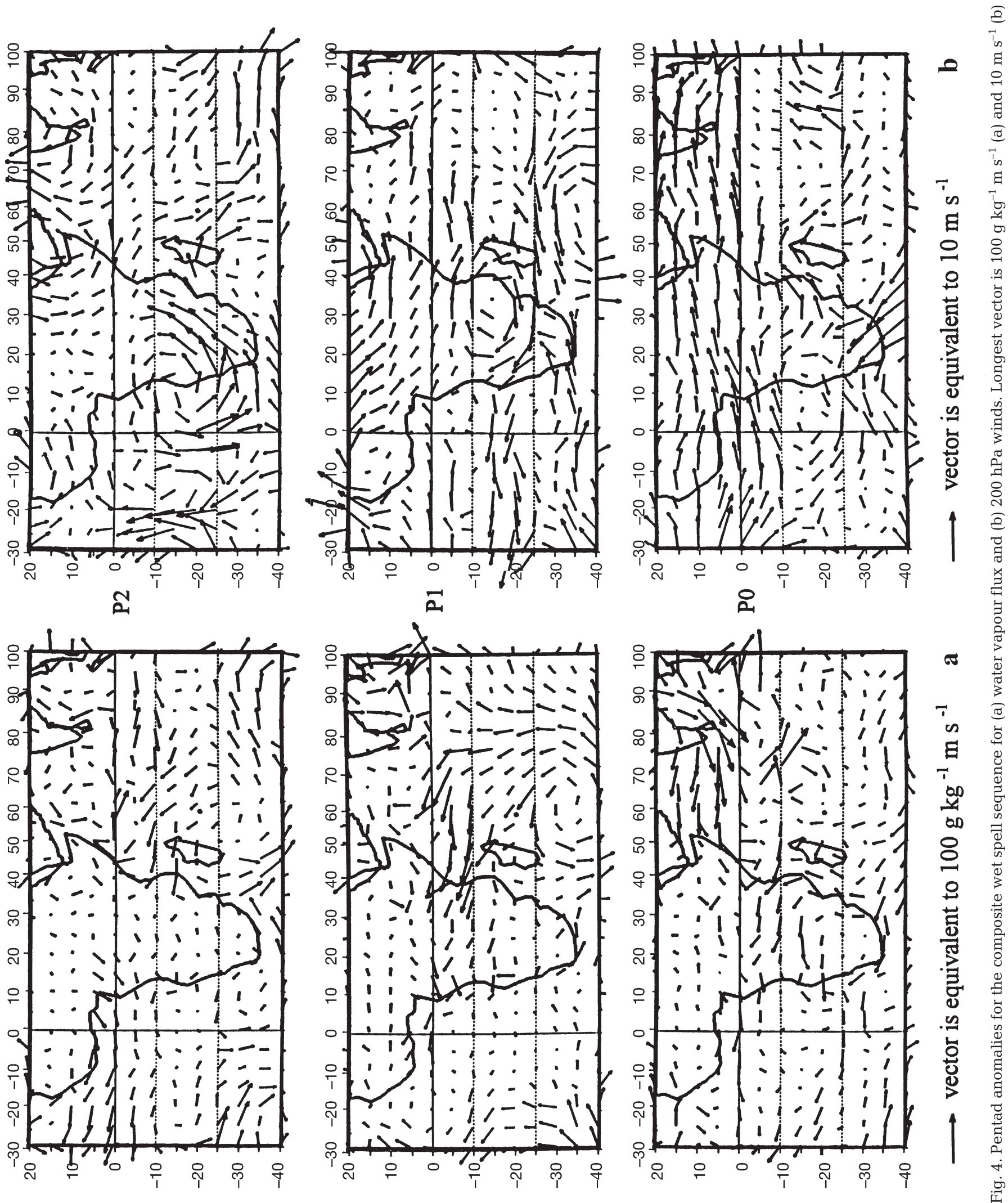
Upper wind anomalies during the development (P1) and maturity (P0) stages are from the west over tropical Africa, and sourced from the southwestern Sahel, northern Congo Basin, and the tropical east Atlantic Ocean. This finding is in agreement with the similar work of Mutai \& Ward (1998).

The velocity potential of the WVF field is useful in identifying thermodynamic mechanisms underlying cumulus convection. Atmospheric energy sources and sinks can be assessed for intra-seasonal oscillations at regional scales (Chen \& Tzeng 1990). Divergent WVF anomalies are illustrated in Fig. 5a with vector length proportional to the gradient of the velocity potential. At the formation stage (P2) a divergent center occurs southeast of Madagascar in the southwest Indian Ocean. A line of convergence occurs off the Somali coast, whilst convergence dominates over the Atlantic Ocean. At the onset stage (P1), divergence in the south Indian Ocean intensifies and shifts northward. Convergence over Tanzania is intensified as expected. Weak divergence east of South Africa, over the Atlantic Ocean and west Africa is in contrast with convergent moist fluxes over the Congo Basin and Angolan coast. The Indian Ocean divergent cell collapses at the maturity stage (P0) and is replaced by weak convergence. Convergence over Tanzania is conspicuous and contributes to a sharp increase in equivalent potential temperature in the surface layer. The main feature of the WVF divergent circulation anomalies is the southward shift of a line of anomalous confluence from the Arabian Sea to northern Tanzania from P2 to P0.

Fig. 6a illustrates the precipitable water (PW) anomalies in sequence. In the formation stage (P2), a thin NW-SE band of positive PW anomalies is located over equatorial east Africa and the western Indian Ocean. Most of southern Tanzania is covered by negative anomalies. At the onset stage (P1), the thin band of moisture expands into a larger cell of positive PW anomalies covering east Africa and extending offshore to $60^{\circ} \mathrm{E}$. Near the equator, $\mathrm{PW}$ anomalies are $>+3 \mathrm{~mm}$. Negative values cover central and southern Africa and the rest of the Indian Ocean. A gradual merging of positive PW anomalies from the tropical Atlantic and Indian oceans occurs by P0. Negative anomalies are found in the Mozambique Channel, and across the central Indian Ocean and Sahara Desert region.

The vertical motion field (Fig. 6b) indicates areas of subsidence and ascent (negative) where diabatic heating anomalies are large. During the formation stage (P2) strong rising motions occur in a NW-SE band over the western Indian Ocean and extend over Kenya. In the onset stage (P1), centres of vertical uplift are displaced westward. Most of Tanzania is under rising motion, while sinking motion intensifies in the central and south Indian Ocean. Strong uplift anomalies occur over east Africa, Angola and the Congo Basin during the maturity stage (P0) as expected. Subsident motions intensify over India at this stage. Westward coalescence of the NW-SE band from the Indian Ocean with uplift over the mountains of northern Tanzania is the main feature of the vertical motion anomaly sequence.

\section{DISCUSSION AND CONCLUSIONS}

Economic development in Tanzania depends largely on the climate-driven agricultural sector, which is plagued by rainfall variability and forecast uncertainty. The rainfall distribution is bimodal, one season centered on April and the other on November. This paper has focused on the seasonal onset of 'short' rains in November, which experience a year-to-year standard deviation equivalent to the mean $(\sim 100 \mathrm{~mm})$. Composite anomaly patterns for major wet spells illustrate the presence of a strengthened anticyclone over the southwest Indian Ocean and associated westward fluxes of moisture. Together with northeast fluxes from the Arabian Sea, a line of confluence is maintained so that uplift of moist unstable air is sustained over northern Tanzania. Compensating sinking motions occur over the south Indian Ocean before the event and over India during the wet spell. Convection is enhanced by an increase of upper westerlies in the equatorial band, which assists overturning and convective outflow. In both P2 and P0 patterns, the upper trough extends equatorward from a cyclonic circulation anomaly over Madagascar. The combined effect of the synoptic forcing is to produce an average of over $100 \mathrm{~mm}$ of rainfall within $10 \mathrm{~d}$.

For predictive purposes water vapor flux anomalies, vertical motion and low-level geopotential patterns show distinctive features during formation and onset stages. By smoothing incoming gridded weather data and subtracting the reference mean, the intra-seasonal convective phase and its synoptic forcing can be determined. This will improve forecast guidance in interpreting medium-range output products, ideal for farming and strategic management.

Further work should include a detailed analysis of easterly confluence and recurvature, and its relationship to convective pulsing, as suggested by Kinuthia \& Asnani (1982). The association between eastwardmoving equatorial and subtropical waves and rainfall in east Africa could be investigated through Hovmoller analysis and vertical section composites. While this study has improved our understanding of intra-seasonal convective forcing in the short rainy season, similar diagnostic work could be done for the long rains after February. 

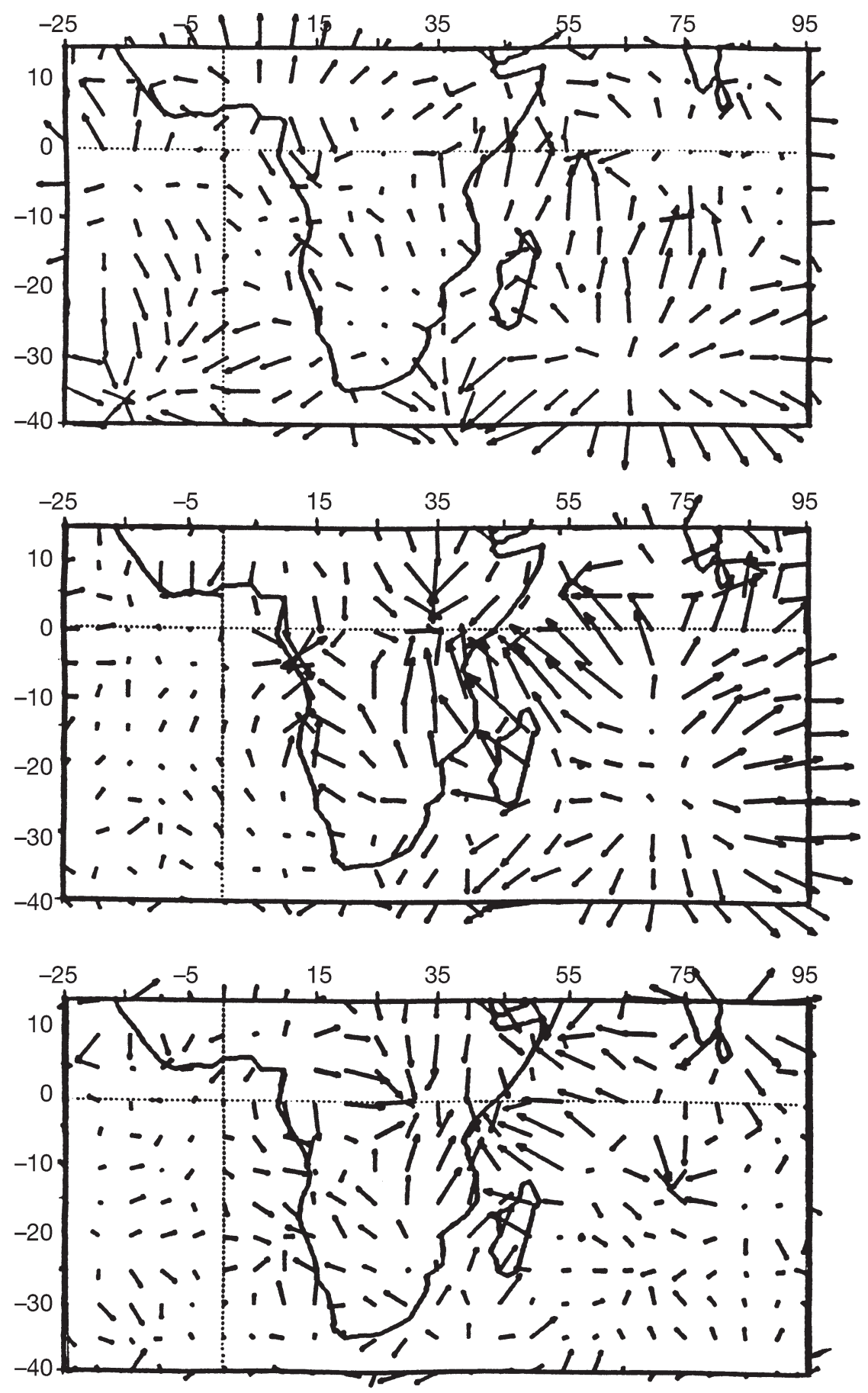

$\rightarrow$ vector is $20 \times 10^{8} \mathrm{~kg} \mathrm{~s}^{-1}$ 

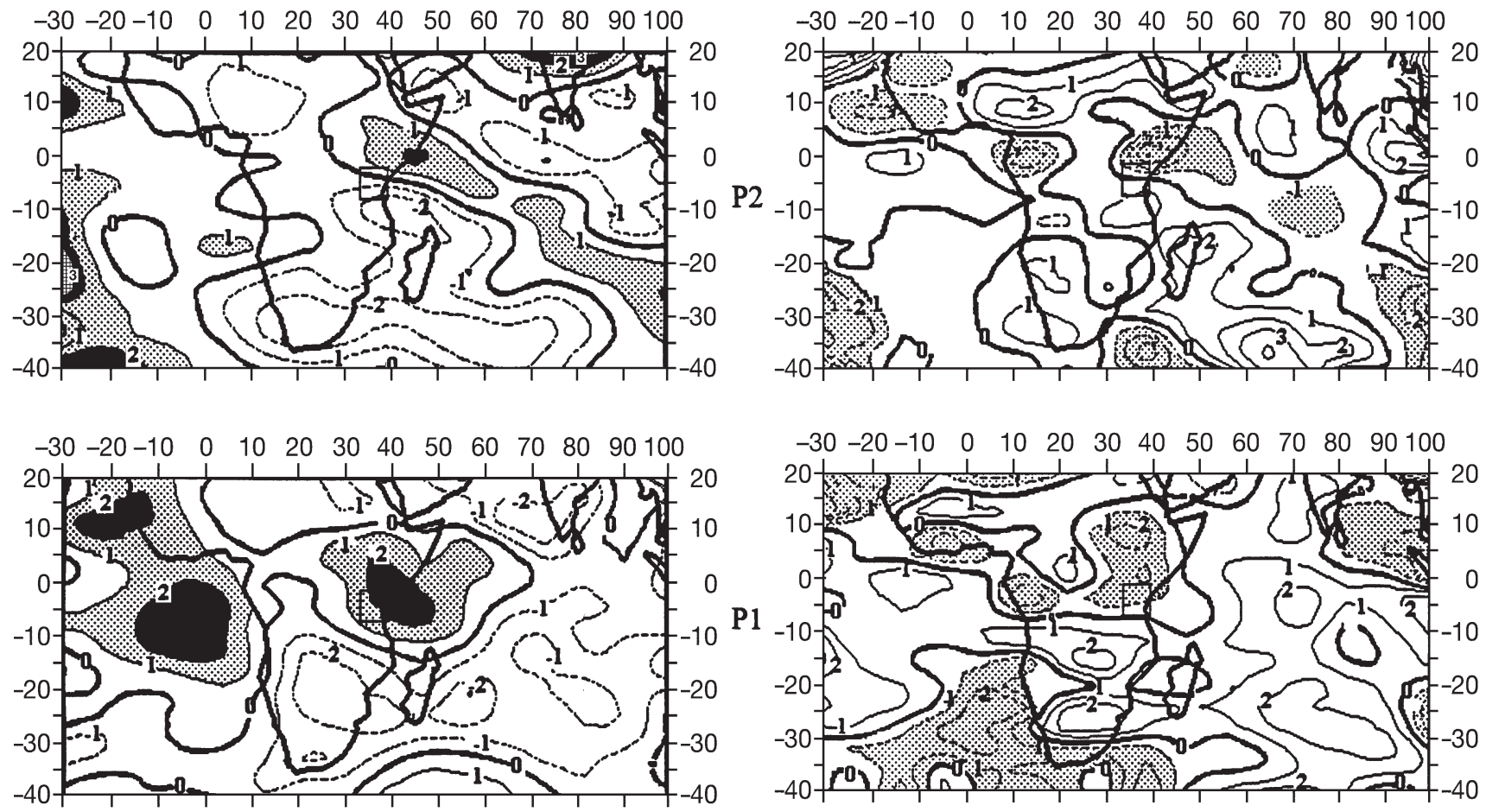

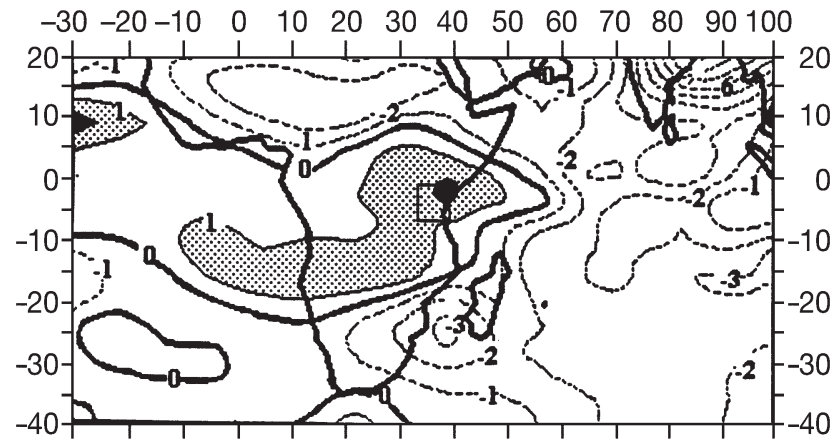

Contour intervals are $1 \mathrm{~mm}$

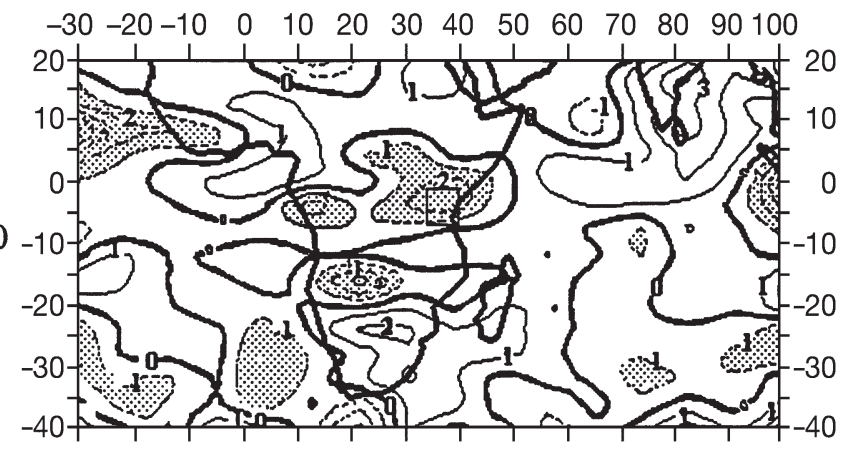

Contour interval is $2 \times 10^{-4} \mathrm{~Pa} \mathrm{~s}^{-1}$

Fig. 6. Pentad anomalies for the composite wet spell sequence for (a) precipitable water and (b) 500 hPa vertical motion. Units are $\mathrm{mm}(\mathrm{a})$ and $\mathrm{Pa} \mathrm{s}^{-1}$ (b)

Acknowledgements. Rainfall data were supplied by the Tanzania Directorate of Meteorology. Gridded weather data were obtained from the ECMWF. The research was supported by the Foundation for Research Development of South Africa and undertaken in the Oceanography Dept, University of Cape Town.

\section{LITERATURE CITED}

Anyamba EK (1992) Some properties of a 20-30 day oscillation in tropical convection. J Afr Meteorol Soc 1:1-19 Asnani GC (1993) Tropical meteorology. Noble Printers, Pune Bengtsson L, Shukla J (1988) Integration of space and in situ observations to study global climate change. Bull Am
Meteorol Soc 69:1130-1143

Cadet DL (1985) The Southern Oscillation over the Indian Ocean. Int J Climatol 5:189-212

Chen TC, Tzeng RY (1990) Global scale intra-seasonal and annual variation of divergent water vapour flux. Meteorol Atmos Phys 44:133-151

Hastenrath S, Nicklis A, Greischar L (1993) Atmospherichydrospheric mechanisms of climate anomalies in the western equatorial Indian Ocean. J Geophys Res 98(C11): 20219-20235

Hoskins BJ, Hsu HH, James IN, Masutani M, Sardeshmukh PD, White GH (1989) Diagnostics of the global atmospheric circulation based on ECMWF analysis 1979-1989. Tech Doc 326, WMO, Geneva

Kabanda TA (1995) Seasonal and intra-seasonal dynamics 
and precursors of rainfall over northern Tanzania. MSc thesis, Oceanogr Dept, University of Cape Town

Kabanda TA, Jury MR (1999) Inter-annual variability of short rains over northern Tanzania. Clim Res 13:231-241

Klinker E (1991) Aspects of large scale modelling, energy and water cycles in the climate system. NATO ASI Series 21, p 43-67

Levey KM (1993) Intra-seasonal oscillations of convection over southern Africa. MSc thesis, University of Cape Town

Makarau A (1994) Intra-seasonal oscillatory modes of the southern Africa summer circulation. PhD thesis, University of Cape Town

Matarira CH, Jury MR (1992) Contrasting meteorological structure of intra-seasonal wet and dry spells in Zimbabwe. Int J Climatol 12:165-176

Murakami T (1988) Intraseasonal atmospheric teleconnection

Editorial responsibility: Hans von Storch,

Geesthacht, Germany patterns during the northern hemisphere winter. J Clim $1: 117-131$

Mutai CC, Ward MN (1998) Predictability of the east African short rains on intraseasonal to interannual timescales. Proc 23rd Climate Diagnostics Workshop, Miami, p 23-46

Nyenzi BS (1988) Mechanisms of East African rainfall variability. PhD thesis, Florida State University, Tallahassee

Ogallo LJ (1989) The spatial and temporal patterns of the East African seasonal rainfall derived from principle component analysis. Q J R Meteorol Soc 494:145-167

Rui H, Wang B (1990) Development characteristics and dynamic structure of tropical intraseasonal convection anomalies. J Atmos Sci 47:357-379

Zhu B, Wang (1993) The 30-60 day convective seesaw between the tropical Indian and Western Pacific Oceans. J Atmos Sci 50:184-199

Submitted: December 20, 1998; Accepted: August 2, 1999

Proofs received from author(s): August 8, 2000 